\title{
Regulatory System Reform \\ to Support Natural Gas Market \\ Liberalisation
}

\subsection{Direction of Reforms}

Summarising international experience in relation to natural gas market reform, while giving special consideration to China's specific situation, the creation of a natural gas market system and reform of administrative systems should embody the principles described below.

The direction taken by reforms should be identical to the direction taken in the creation of a socialist market economic system. The creation of a market economy with specific Chinese socialist characteristics has been the overall direction adopted in the reform of Chinese economic systems. Statements issued during the 18th plenum of the People's Congress also made new proposals regarding the refinement of the socialist market economy system. The reform of the natural gas market must satisfy the requirements of a socialist market economy, ensuring that the relationship between the government and markets is dealt with effectively, in particular requiring the transformation of governmental functions. This applies particularly in the clarifying of the boundaries between the government and its markets; this will provide oil and gas companies with more opportunities to

\footnotetext{
* This chapter was overseen by Xiaoming Wang from the Development Research Center of the State Council and Mallika Ishwaran from Shell International. It was jointly completed by Yusong Deng, Jiaofeng Guo, Shouhai Chen from China University of Petroleum and Qingle Wu from Shell China. Other members of the topic group participated in discussions and revisions.
}

develop. At the same time, in addition to providing the basic functions of a market system in optimising and allocating resources, it must improve the macroeconomic and market regulatory roles of the government, allowing implementation of effective regulation of naturally monopolistic markets while encompassing the important society-wide functions of safety, energy efficiency and emissions reduction regulation, in addition to evening out various flaws within the market.

Reforms must be implemented according to both long-term and short-term goals, taking place gradually. Natural gas is a basic element of our national economy; the reform of the natural gas industry must take into consideration both the positive and the negative impacts on socioeconomics, and this requires us to keep our eyes on the bigger picture, while establishing new system mechanisms. At the same time as we seek to implement these in the present, we also need to be able to solve current problems as they appear. This requires a unified design, which establishes the direction and objectives of such reforms, while allowing special emphasis to be placed where necessary, dealing first with the easier objectives and then the more difficult ones, first building up experience from trials, followed by gradual extension, followed by step-by-step implementation.

Reforms must ensure that they are all-encompassing and that the burden of them is shared evenly. Sufficient consideration must be given to the ability of different industrial sectors 
to withstand adjustments in pricing, and to their different requirements in terms of the adjustment process. Special consideration must also be given to the harmonising of international and domestic market prices, and to the ability of both urban and rural residents to withstand such changes. The creation of new systems and procedures should ensure that reform of the market, the administrative system and pricing reform occur in step with reforms to taxation, while making active efforts to ensure the sustainable development of the natural gas industry.

The objectives of reforms should be closely linked to increasing industrial competitiveness. As globalisation takes on even greater economic significance, the rate at which China's oil and gas industries are becoming involved internationally, in addition to inviting international involvement in China, is increasing, and against this backdrop increasing the competitiveness of our energy industry is a matter of a major urgency. Reform of the natural gas industry must be linked to the creation of a more competitive industry. Whether or not China's oil and gas industries become more competitive internationally is a major benchmark against which we can measure the success of market reforms. Allowing competition to enter our markets will ensure that our oil and gas industries become more efficient and scientifically advanced, thus increasing the competitiveness of our industry.

\subsection{Key Pillars of Reform}

Reforms must follow the proposals aired at the 18th plenum of the People's Congress concerning completion of a market economy with specific Chinese socialist characteristics, which would allow markets to play a definitive role in the allocation of resources, accelerating the transformation of government functions, reducing bureaucratic red tape and interference in microeconomic activities and establishing a service-based natural gas administrative system. Reforms should be sufficiently market-oriented, while establishing pricing parity between natural gas and alternative energy sources, in addition to creating pricing systems that reflect the extent of scarcity of resources, the market relationships of supply and demand and environmental externality in the creation of a green financial and taxation system. This will introduce the diversity of competition to the overall natural gas production chain, increasing external access yet taking care to ensure that the state retains control over the economy, enhancing regulation in terms of fair extension of access to services, while establishing a diversified, competitive, open and orderly modern market system. In overall terms, in order to guarantee that the strategic objectives regarding the development of natural gas in China are achieved, the natural gas market liberalisation reforms should accelerate the establishment of three main pillars, as outlined below.

\subsubsection{Pillar I: Establish a Diversified, Competitive, Open, Orderly Modern Natural Gas Market System}

The natural gas market liberalisation reforms mainly cover three areas. The first is the breaking up of monopolies, encouraging diversification and competition among participants. The introduction of private capital into the oil and gas exploration field should be supported, allowing its participation in conjunction with state oil and gas companies in oil and gas exploration and development. Reform of the current oil and gas mineral rights allocation regime, gradually allowing competitive tendering and bidding for quotas, based on implementation of a licensing regime, would then allow the structure of a competitive oil and gas resource exploration and development market to be established. Encouraging diversification of natural gas importers will attract private capital for the construction of oil and gas pipelines, which will then allow the separation of natural gas transport and sales. At the same time, it will make it possible to ensure that access to the midstream and downstream sectors is allowed on the basis of company safety, energy efficiency, environmental, quality and technical performance indices. 
The second area is the acceleration of the creation of a natural gas trading market, involving training market intermediary organisations and ensuring an improvement in service. The construction of the Shanghai Oil and Natural Gas Trading Centre should be accelerated. In addition, at an appropriate time, research should be carried out regarding the creation of natural gas trading platforms for Beijing, Tianjin, Guangzhou, Chengdu and other trading centres. Encouragement should be given to energy efficiency conversion, financial, insurance, IT, consulting and other such participating professions, in order to improve the professional standards of all involved.

The third area is deepening the extent of reform of state-owned enterprises, encouraging the growth of modern energy companies. This can be accomplished by:

- promoting reforms such as mixed ownership, allowing private companies and overseas investors to hold shares in state-owned energy companies, as well as refining the process by which state-owned energy companies may list on the stock exchange, creating a diversified ownership structure while maintaining a state-owned controlling share over natural monopolies;

- optimising corporate governance structures in state-owned enterprises, introducing modern business regimes, creating boards of directors that are more than just symbolic and allowing shareholder meetings and other similar business administration and decision-making structures;

- tightening up company budgetary and expenditure management, ensuring cost-effective accounting, while giving full consideration to the social function of such enterprises, historical problems and future developmental requirements, increasing the proportion of profits being passed on, and ensuring that excess profits arising due to monopolies revert to the public coffers and go to benefit everyone.

\subsubsection{Pillar II: Create a Pricing System that Reflects the Extent of Scarcity of Resources, the Market Relationships of Supply and Demand and Environmental Externality and a Green Financial and Taxation System}

Natural gas pricing reform and financial and taxation reform must be dealt with in five ways:

- ensure that there is a mechanism by which competition in the natural gas industry results in market adjustments, and that natural monopolistic mechanisms are subject to legal regulation;

- internalise the costs of externalities such as environmental protection that required in the course of exploitation of energy resources and reduction of greenhouse gas emissions, which will go towards establishing energy pricing parity;

- bring about gradual integration with international natural gas markets;

- adopt natural gas as a clean and highly efficient energy type, with major encouragement being given to increased production capacity and importing;

- eradicate cross-subsidisation, which will ensure that "hidden subsidies" become "known subsidies".

In terms of pricing reform, it will be necessary to improve the "market netback" laws. This will allow regular dynamic adjustments correlating to energy resources, including pricing, category selection and weighting correlating to energy resource. Dynamic upstream and downstream linkage systems must be put in place, allowing for locally created price transmission systems, in addition to refining mechanisms via which low-income groups will receive financial subsidies. Creation of the Shanghai Oil and Natural Gas Trading Centre should be accelerated, while the scope of the trial should be 
extended. The introduction of differential pricing policies should be brought forward, encouraging the introduction of stepped prices and peak price adjustment etc. Once the market structure and other conditions allow, competitive systems should be introduced, allowing suppliers and users to determine prices freely. Once natural gas trading centres have been established, this will act as the basis for establishing and adjusting market prices and lead to the creation of a gas storage market and a pipeline market, allowing market forces to provide a solution to peak storage problems.

In terms of financial and taxation reform, it will be possible to create a green energy taxation system, which will act as a major financial stimulus in the development of natural gas. Then, at an appropriate point, carbon tax should be introduced, with "emissions charges" being converted to an "emissions tax" with the introduction of collection of an ad valorem natural gas resources tax, in conjunction with introduction of an energy efficiency/emissions reduction quota trading system. By increasing the financial support for infrastructure construction, scientific innovation, energy efficiency and safety assurances, it will be possible to accelerate reforms of the pipeline and storage infrastructure financing and investment systems. The duration of subsidies for shale natural gas and other non-conventional forms of natural gas should be extended and tax breaks offered to interruptible users, which in turn will increase research in terms of energy efficiency and emissions reduction within the industry as a whole. Strategic storage costs should be included in financial budgeting in addition to establishing a system of subsidies for low-income groups.

\subsubsection{Pillar III: Establish a Service-Centred Natural Gas Administration with a Legal Basis}

The transformation of government functions should be accelerated, reducing bureaucratic red tape and interference in microeconomic activities. Natural gas administrative bodies should mainly be concerned with macroeconomic administration relating to the field of natural gas. The formulation and realisation of oil and natural gas-related law and related policy strengthening will establish a developmental strategy that gives priority to energy efficiency, providing the capacity to respond to climate change and guide society as a whole in the direction of reduction of emissions and sustainable development. This should also entail enhanced macroscopic planning and industry guidance while reducing regulatory control over project approvals and pricing, thus reducing the level of interference in terms of market operations, production and other business activities. Enhanced demand-side management of gas-using industries is necessary, with greater attention being paid to long-term energy efficiency and greenhouse gas emissions management. At the same time, attention must be paid to ensuring the security of natural gas supplies; international co-operation should be encouraged, combining increased "Chinese external involvement" and "international involvement within China", improving reserve management capabilities and ensuring effective resource alerts and prediction.

Enhanced social oversight should be put in place through the creation of a service-centred natural gas administrative system. Natural gas regulatory bodies should mainly be concerned with market malfunction, with their main efforts being concentrated on their regulatory role. They must act appropriately in the regulation and encouragement of fair competition and the prevention of market monopolies. They need to extend their regulatory functions to include natural gas pipeline development and other areas where natural monopolies may exist, as well as the regulation of market prices and other aspects. In addition, they must be responsible for safety of operations, pollutant discharge and emissions as well as ensuring fairness of service and protecting the rights of consumers. They should be capable of ensuring compliance, strengthening production safety and improving levels of energy efficiency and environmental protection, 
ensuring that development is sustainable and making the social accountability of businesses a priority.

\subsection{Reform Objectives}

Full advantage should be taken of the strategic possibilities for reform that present themselves at this time of massive drops in international oil prices. Any actions should be taken according to the requirements of Chinese socialist market economic development, taking advantage of the definitive effect that markets play in the allocation of resources and making more effective use of the role played by the government, in order to support the establishment of "an effective government + an effective market". This approach will result in the creation of a mechanism for natural gas pricing mainly determined by market forces. The transformation of the government approach to regulation will result in the creation of a comprehensive oil and natural gas-related system of legislation, the founding principles of which are encouragement of independent control of businesses over their operations, fair competition, freedom of choice for consumers allowing them greater control over expenditure, free movement of commercial factors and equality in exchange. This will in turn ensure an effective, competitive market structure and market system, resulting in the overall advancement of reforms in the field of natural gas while both promoting and accelerating energy resource reforms in China.

Establish a comprehensive system of natural gas related legislation and standards: A "comprehensive legal system" means a national legal system which is complete, standardised, systematic, harmonised and unified. This should embody the legal principles of socialism with Chinese characteristics, providing a completely standardised legal system, with an effective system for the implementation of such laws. It should also be a system capable of rigorous monitoring of the law, which also consists of a system of legal guarantees, whereby national order is enforced according to the law, involving both governing by law and the government acting according to the law, in supporting the creation of a unified legal state, legal government and legal society. This in turn ensures that laws are scientifically established, strictly enforced, formulated fairly and obeyed by society, in a manner capable of modernising China's governance systems and capabilities. Regarding natural gas, legislative revision should occur rapidly, as there is a legal basis for the introduction of major reforms, while policy should be closely connected with such legislation. Moreover, there should be increased governance according to law, ensuring that industry administration occurs on a legal basis, ensuring fair legal process, enhancing the public's faith in the judicial process. Finally, increased work should occur in relation to the creation of legal teams and enforcing a restriction list, thereby ensuring that "no actions should be taken without a legal basis, while legal responsibilities must be fulfilled".

Create a new kind of integrated, open, competitive, orderly natural gas market system: The modern market systems must be integrated in nature, relying on the interaction and interconnection of a number of submarkets which are organically integrated. Integration, openness, competition and order are all essential characteristics of a market economy. Integration is the foundation of economic development, with products and factors able to flow between different industries, departments, regions, both domestically and internationally. Openness is a prerequisite in terms of economic vitality-in terms of the international division of labour, Chinese companies exhibit a major strength in that they are responsible for making products more competitive in the international production chain, increasing the efficiency of allocation of resources within specific sectors. Competition is the foundation of all economic efficiency, and fair competition with only the fittest surviving is crucial to ensure improved economic quality and efficiency. Order relates to maintaining economic order, requiring the establishment of strict, fair, open and transparent market regulations, which then maintain effective order within markets. Only by establishing an integrated, open, 
competitive and orderly market system is it possible to ensure that market factors are able to play a full role, which in turn will result in resources being allocated in the most efficient manner. This can be achieved via an overall increase in the extent of reforms extending as far as 2030, which will result in the creation of an integrated, open, competitive, orderly and modern oil and natural gas market system formed of a number of very large oil and gas companies in conjunction with other oil and natural gas production, transport and sales operators with different ownership structures and of differing size.

Creation of pricing systems and a financial and taxation system that reflect the extent of scarcity of resources, the market relationships of supply and demand and environmental externality: The system via which natural gas prices are set should be transformed from being government-dictated to being market-moderated, and this in turn will ensure that prices fall in step with those on the international natural gas markets. The pricing parity relationships between natural gas and alternative energy sources must be reorganised, and a financial and taxation system that takes into account ecology and environmental protection, reduction in greenhouse gas emissions and other such externalities must be established.

Encourage the creation of a modern natural gas market supervision system which is all-encompassing, where rights and duties are clearly delineated and which is both fair, transparent, efficient and capable of effective regulation: The manner in which the government implements supervision over the natural gas industry, which relied in the past mainly on an application and approval system, should be converted to one in which it has a strategic role in planning and guidance. This will encourage the creation and completion of a market regulatory system, improving the social accountability of government, the increased accountability encouraging fairer competition, preventing market monopolisation and protecting consumer rights at the same time as ensuring the safety of production operations; it will also provide encouragement to reduce the levels of pollutant emissions in addition to providing an impetus for sustainable social and economic development.
Open Access This chapter is licensed under the terms of the Creative Commons Attribution 4.0 International License (http://creativecommons.org/licenses/by/4.0/), which permits use, sharing, adaptation, distribution and reproduction in any medium or format, as long as you give appropriate credit to the original author(s) and the source, provide a link to the Creative Commons license and indicate if changes were made.
The images or other third party material in this chapter are included in the chapter's Creative Commons license, unless indicated otherwise in a credit line to the material. If material is not included in the chapter's Creative Commons license and your intended use is not permitted by statutory regulation or exceeds the permitted use, you will need to obtain permission directly from the copyright holder. 